\title{
COMPARANDO A ABRANGÊNCIA DO BALANCED SCORECARD COM OS MODELOS DO TQC E PNQ
}

\author{
Walter Gassenferth ${ }^{1}$ \\ Maria Augusta Soares Machado ${ }^{2}$
}

Resumo: Este estudo descritivo estatístico, baseado em pesquisa realizada pela Fundação Dom Cabral, apresenta uma comparação da abrangência dos modelos BSC, TQC e PNQ, como ferramentas de controle de desempenho, a partir dos resultados de pesquisa realizada com as 500 maiores empresas privadas que atuam no mercado brasileiro, de acordo com a Revista Exame de Junho de 2000. O estudo também procura identificar as características destes três modelos de avaliação de desempenho empresarial, visando estabelecer uma matriz comparativa que possa servir de base para orientar a seleção de um modelo de controle de desempenho adequado à realidade de cada empresa. Acredita-se que este estudo será relevante para empresas que estejam considerando o Balanced Scorecard apenas como uma ferramenta de suporte ao desenvolvimento e implementação da estratégia da empresa.

Palavras-chave: Balanced Scorecard, TQC, PNQ, Controle de Desempenho.

Abstract: This statistical descriptive study, based on a research conducted by Fundação Dom Cabral, presents a wideness of range comparison among BSC, TQC and PNQ models, as performance control tools, departing from the results of a research took in effect with the 500 biggest private companies operating in Brazilian market, according to Exame Review, June of 2000 edition. The study also identifies the main characteristics of these three enterprise's performance evaluation models, trying to establish a comparison matrix that will be the drive to a performance control model selection, suitable to each company reality. This study can be relevant to organizations which considers the Balanced Scorecard only as a support tool to their strategy development and implementation.

Key-words: Balanced Scorecard, TQC, PNQ, Performance Control.

\footnotetext{
1 wgassenferth@timbrasil.com.br

2 IBMEC, mmachado@ibmecrj.br
} 


\section{INTRODUÇÃO}

A pesquisa, realizada pela Fundação Dom Cabral, teve como universo pesquisado as 500 maiores empresas privadas que operam no país, considerado o critério de classificação das 500 maiores feito pela Revista Exame Melhores e Maiores, de Junho/2000. A pesquisa realizada foi quantitativa, buscando-se para todas as questões critérios quantificáveis de avaliação. Os questionários para a coleta das informações também foram estruturados e auto-aplicáveis, tendo sido enviados por mala direta às empresas do universo pesquisado. Esta pesquisa foi conduzida pela FDC entre os meses de Abril e Junho de 2002, junto a 377 empresas, dentre as 500 Maiores e Melhores da Revista Exame, selecionadas por serem aquelas que mais têm respondido a questionários enviados. Dessas, 98 responderam ao questionário e tiveram respostas válidas às questões apresentadas. Esta amostra, por quatro critérios relevantes, mostrou-se altamente satisfatória, do ponto de vista de sua representatividade estatística, com bom nível de aderência ao universo. Estes testes foram realizados pela FDC e tomados aqui como dado deste trabalho (GASSENFERTH, 2005).

\section{O CONCEITO DE CONTROLE DE DESEMPENHO E SEUS DESDOBRAMENTOS}

A mensuração de desempenho visa fornecer uma indicação para os gestores do que se fez e como se fez, para que o sistema possa ser continuamente melhorado e os membros da organização possam ser alinhados em direção aos objetivos estratégicos. Um sistema de mensuração deve capturar e organizar dados, além de comunicar os resultados de forma rápida e clara, permitindo a cada membro da organização tomar as providências necessárias à melhoria do desempenho global da empresa. O sucesso de um sistema de medição de desempenho está baseado nos seguintes princípios:

- Medir somente o que é importante; medir coisas que dêem impacto ou indiquem o sucesso organizacional.

- Equilibrar um conjunto de medidas. Procurar, no momento de definir medidas, considerar as perspectivas das pessoas que tomam decisões (acionistas, alta gerência e clientes).

- Oferecer uma visão, tanto da gestão dos recursos da organização quanto da gestão dos resultados da organização.

- Envolver os membros da organização no desenho e na implementação do sistema de medidas.

- Alinhar as medidas com os objetivos e as estratégias organizacionais.

De acordo com Sink e Tuttle (1989), o uso eficaz de um sistema de mensuração pode ser prejudicado por alguns paradigmas, como aquele que considera a mensuração uma ameaça, ou o que considera que medidas devem ser pautadas unicamente em precisão, ou o que enfoca um único indicador dando ênfase apenas a produtividade do trabalho, encarando os aspectos qualitativos da medição como sendo uma subjetividade não confiável, ou ainda aquele que considera a padronização como fator limitante do bom desempenho de um trabalho. Para Sink e Tuttle (1989) a quebra destes paradigmas é fundamental para o desenvolvimento de um sistema eficaz de indicadores. Também recomendam que se desenvolvam medidas a partir de uma visão sistêmica da organização, com indicadores essenciais que meçam as grandezas de forma absoluta com critérios de medição muito bem explicitados, em especial em sua aplicação e descrição.

Certo e Peter (1993) afirmam que as medições de desempenho podem ser 
quantitativas ou qualitativas, ou podem combinar estas duas formas, que tem seus pontos fortes nos padrões e conformidades, do enfoque quantitativo, com a criatividade e a visão pró-ativa dos negócios, do enfoque qualitativo.

Merchant (1982), afirma que o processo básico de controle envolve três passos: Estabelecer padrões, medir o desempenho comparando-o com estes padrões e corrigir desvios detectados no estabelecimento destes padrões e nos planos de onde se originaram os resultados. O controle dos resultados pode gerar um grande e não pretendido efeito negativo, caso os critérios de medida não sejam definidos de forma satisfatória. Também afirma que o estudo prévio da situação e do ambiente onde o controle será utilizado é de grande importância na construção de um sistema adequado de controle.

Estudos sobre medidas de avaliação do desempenho das organizações têm evidenciado uma forte correlação entre o processo de tomada de decisões operacionais e estratégicas e a utilização de medidas não-financeiras. Mais precisamente esse é o caso da pesquisa conduzida por Ittner e Larcker (1998), que investigou o uso de medidas nãofinanceiras, em especial a satisfação dos clientes como indicador do desempenho financeiro, e do estudo de Banker et al. (2000) sobre planos de incentivo que incluíam medidas de desempenho nãofinanceiras como critério de compensação. Para empresas prestadoras de serviços o uso de medidas nãofinanceiras pode levar ao conhecimento mais profundo do posicionamento competitivo do seu negócio através da visão dos clientes e competidores.

Sharman (1995) também sugere seis passos para o desenvolvimento de um sistema de mensuração de desempenho:

Passo 1: Análise Estratégica. Visa entender a posição atual e futura da companhia, avaliar as necessidades dos stakeholders para, a partir de fatores críticos de sucesso, poder definir as medidas internas a serem perseguidas. Esta análise permite o mapeamento das ligações entre estratégia e processos, e das relações da empresa com o ambiente, com outras organizações e com a sociedade em que está inserida.

Passo 2: Definição dos Processos. Promove a compreensão de todos os componentes do processo. Não só insumos e produtos, bem como as relações entre os processos, formando-se um mapa detalhado do pedaço da cadeia de valor que afeta diretamente o cliente.

Passo 3: Desenvolvimento de Medidas. Elaborado por grupos representativos das áreas funcionais, começa pela saída esperada, passando para o fim do processo, até chegar o início do processo. As medidas são traduzidas em termos quantitativos ou qualitativos, dependendo do tipo de processo que está sendo trabalhado e deverão ser validadas pelos gestores e posteriormente refinadas.

Passo 4: Mensuração do Desempenho. Parte da premissa da existência de um Sistema de Informações Gerenciais (SIG) para suportar a automação das medições, que deve levar em conta seis dimensões de desempenho: duas relacionadas com o resultado do sucesso competitivo e quatro com os aspectos determinantes deste sucesso. Como exemplo de medidas do resultado do sucesso competitivo, podemos citar os indicadores de "competitividade" (participação de mercado) e os financeiros (custo unitário, lucro e valor adicionado). Como indicadores determinantes do sucesso competitivo, podemos citar: qualidade, flexibilidade, utilização de recursos; e iniciativas de inovação. A coleta de dados reais sobre o desempenho, pressupõe a existência de uma estrutura de mensuração definida, além da a definição de responsabilidades pelas medidas e rotina de coleta, bem como pelo estabelecimento de relatórios e de requisitos de distribuição de informações. 
Passo 5: Análise de Lacunas. Nesta etapa são avaliados o desempenho atual, sua distância do padrão pré-estabelecido, as oportunidades de melhoria de performance. Planos de melhoria são desenvolvidos nesta fase visando aumentar o desempenho no próximo período de avaliação.

Passo 6: Implementação. Aqui são implementados os planos de melhoria, bem como são revistas as metas estratégicas e os planos como um todo, em busca de um novo patamar de realizações. Uma vez analisados todos os dados sobre o desempenho real e comparados à estratégia, as prioridades de melhoria podem ser ordenadas, e novas metas propostas.

\section{O MODELO DO PRÊMIO NACIONAL DA QUALIDADE (PNQ)}

Em outubro de 1991, trinta e nove organizações de destaque no cenário nacional como as empresas XEROX, VARIG, PHILIPS, SIEMENS, WEG, dentre outras, instituíram a Fundação para o Prêmio Nacional da Qualidade (FPNQ), para administrar o Prêmio Brasileiro que foi criado com base no Malcolm Baldridge National Quality Award, dos EUA.

Bastante voltados, de início, ao espírito do TQC, os Critérios de Excelência do PNQ foram evoluindo, cada vez mais em direção a excelência do desempenho empresarial como um todo. Hoje, esses Critérios orientam a gestão de muitas empresas e servem de instrumento de avaliação do seu desempenho. De acordo com a FPNQ (2004), o Modelo de Excelência do PNQ compõe-se de sete Critérios de Excelência que se referem a:

1 - Liderança

2 - Estratégias e Planos

3 - Clientes e Sociedade

4 - Informação e Conhecimento

5 - Pessoas

6 - Processos

7 - Resultados da Organização.

O Critério Liderança examina o sistema

ENGEVISTA, v. 9, n. 1, p. 35-46, junho 2007 de liderança da organização e o envolvimento pessoal dos membros da alta direção no estabelecimento, na internalização, na disseminação e na prática de valores e diretrizes que promovam a cultura da excelência, levando em consideração as necessidades de todas as partes interessadas. Este Critério também examina como a alta direção analisa criticamente 0 desempenho global da organização.

O Critério Estratégias e Planos examina o processo de formulação das estratégias da organização de forma a direcionar seu desempenho e determinar sua posição competitiva, incluindo como as estratégias, os planos de ação e as metas são estabelecidos e desdobrados por toda a organização. Este Critério também examina como a organização define seu sistema de medição do desempenho global.

O Critério Clientes e Sociedade examina como a organização monitora e se antecipa às necessidades dos clientes, dos mercados e das comunidades, divulga seus produtos, suas marcas e suas ações de melhoria, estreita seu relacionamento com clientes e interage com a sociedade. Este Critério também examina como a organização mede e intensifica a satisfação e a fidelidade dos clientes em relação aos seus produtos e marcas.

O Critério Informação e Conhecimento examina a gestão e a utilização das informações da organização e de informações comparativas pertinentes, bem como as formas de proteção do capital intelectual da organização.

O Critério Pessoas examina como são proporcionadas condições para o desenvolvimento e utilização plena do potencial das pessoas que compõem a força de trabalho, em consonância com as estratégias organizacionais. Este Critério também examina os esforços para criar e manter um ambiente de trabalho e um clima organizacional que conduzam à excelência do desempenho, à plena participação e ao crescimento pessoal e 
da organização.

O Critério Processos examina os principais aspectos da gestão dos processos da organização, incluindo o projeto do produto com foco no cliente, a execução e entrega do produto, os processos de apoio e aqueles relacionados aos fornecedores, em todos os setores e unidades. Este Critério também examina como a organização administra seus recursos financeiros, de maneira a suportar sua estratégia, seus planos de ação e a operação eficaz de seus processos.

O Critério Resultados da Organização examina a evolução do desempenho da organização em relação aos clientes e aos mercados, à situação financeira, às pessoas, aos fornecedores, aos processos relativos ao produto, à sociedade, aos processos de apoio e aos processos organizacionais. São também examinados os níveis de desempenho em relação às informações comparativas pertinentes.

Os sete Critérios de Excelência se subdividem em 26 itens. Os 19 em que se subdividem os 6 primeiros Critérios são chamados de "Itens de Enfoque e Aplicação" e cada um deles é estruturado conforme a dinâmica do "Diagrama de Gestão", reproduzido na figura 1 .

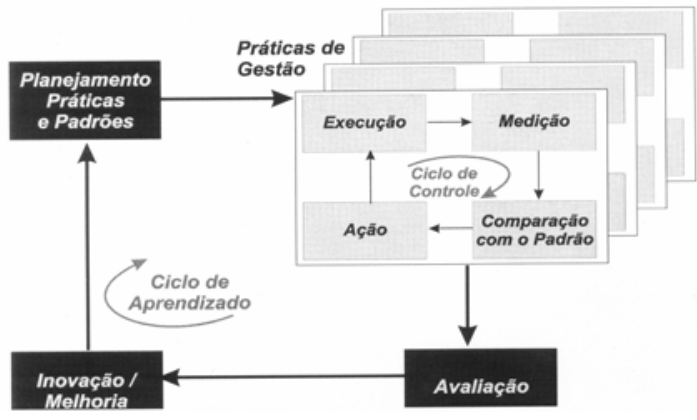

Fonte: FPNQ (2004), p.19.

Figura 1: Estrutura dos Itens de Enfoque e Aplicação

Esse diagrama mostra como se relacionam os 3 tópicos em que se subdivide cada um desses itens: a) Planejamento, Práticas de Gestão e
Padrões de Trabalho; b) Ciclo de Controle e c) Ciclo de Aprendizagem.

O Modelo de Excelência do PNQ é muito útil para avaliação, diagnóstico e orientação de qualquer organização, inclusive instituições sem fins lucrativos e órgãos da administração pública.

\section{O MODELO DO TOTAL QUALITY CONTROL (TQC)}

Também chamado de TQM (Total Quality Management) e GQT (Gerência da Qualidade Total ou Gerência pela Qualidade Total), surgiu do movimento da Qualidade que se iniciou no Japão a partir do início da década de 50, com a forte influência de Deming e Juran.

No Brasil, começou a ser aplicado em meados da década de 80 e até hoje é utilizado, em geral complementado por outros modelos de avaliação.

De acordo com Campos (1996), o TQC trouxe conceitos e métodos que foram muito difundidos, como o novo conceito de Qualidade, o de "cliente interno", o da "cadeia de valor", o Gerenciamento da Rotina (GDR), o Gerenciamento por Diretrizes (GPD), e outras ferramentas que não chegam a ser tão empregadas, como o QFD (Quality Function Deployment), a FMEA (Failure Mode Effect Analysis), a FTA (Fault Tree Analysis).

Enquanto o Gerenciamento da Rotina, no âmbito estritamente funcional, visa, antes de tudo, a manutenção da qualidade com a aplicação do ciclo SDCA, (onde S representa as metas padrão e os procedimentos padrão, sendo D de “do", C de "check" e A de "action"), o Gerenciamento por Diretrizes, de característica basicamente interfuncional, visa à inserção das diretrizes da alta administração, depois de desdobradas, no gerenciamento da organização, em busca de melhorias. Isto se dá pela aplicação do ciclo PDCA, onde o P (de "plan") leva em conta as metas anuais desdobradas. A 
figura 2 ilustra o papel desempenhado pelo Gerenciamento da Rotina e pelo Gerenciamento por Diretrizes, assim como a forma como ambos se relacionam.

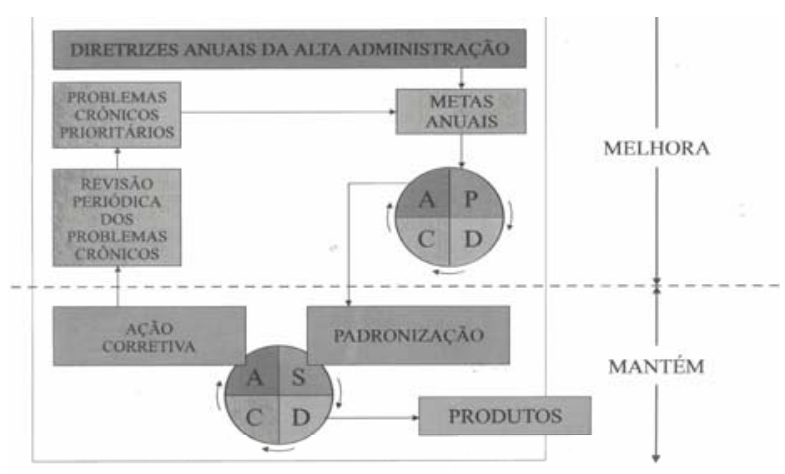

Fonte: Campos (1996), p.270.

Figura 2: PDCA Aplicado com os Objetivos de Manter e Melhorar

O Gerenciamento da Rotina revolucionou a relação homem-processo, especialmente na indústria, criando hábitos de gerenciamento dos processos nos próprios operadores, com a medição de indicadores das características de qualidade de produtos e serviços, instituindo a padronização e disseminando a aplicação do controle estatístico de processos.

Já o Gerenciamento por Diretrizes, quando bem entendido e aplicado, atrelado a um Desdobramento de Diretrizes (DDD) participativo, ainda hoje tem sido empregado como um eficiente meio de internalização dos objetivos estratégicos e das diretrizes deles derivadas, resultando em que cada colaborador, mesmo no nível mais baixo, saiba exatamente o papel que desempenha para a consecução dos grandes objetivos da organização (CAMPOS, 1996).

\section{O BALANCED SCORECARD}

Segundo Hronec (1994), não é simples desenvolver um sistema de medição de desempenho que contemple os interesses de todos os Stakeholders. A diferença de foco entre as estratégias e as medidas de desempenho, encontra-se no eixo dos tempos, pois enquanto uma visa alvos de longo prazo como ser o dominante num nicho de mercado, a outra tem seu foco no cotidiano das operações, como ele se desenvolve e qual a eficiência de sua performance. Esta dicotomia também é refletida nos interesses das gerências, que também são diferentes conforme a posição na hierarquia da organização.

Primeiramente é importante que seja percebido o conceito do Balanced Scorecard para que depois possam ser apresentados os fundamentos que envolvem esta ferramenta. Em seu primeiro livro, Kaplan e Norton (1997) apresentam as medidas do Balanced Scorecard como complementares às tradicionais medidas de desempenho financeiras. Estas derivam da missão e da definição estratégica, que nada mais é que a visão estratégica da empresa, e focalizam o desempenho organizacional sob quatro perspectivas: financeira, dos clientes, dos processos internos e de aprendizado e crescimento. Estas quatro perspectivas formam a estrutura do Balanced Scorecard. Portanto, podemos dizer que no mais alto nível conceitual, o Balanced Scorecard é um modelo que auxilia as organizações a traduzir a estratégia em objetivos operacionais que direcionam comportamentos e performance. As experiências desta ferramenta com diversas empresas mostram que estas utilizam o BSC não só para esclarecer e comunicar a estratégia, mas também para gerenciá-la (KAPLAN e NORTON, 1997).

Muitos são os conceitos que fundamentam esta ferramenta. Estes serão definidos e apresentados no decorrer desta parte do estudo, começando pelas perspectivas que integram a visão de empresa do BSC, na visão de Kaplan e Norton (1996).

Perspectiva Financeira: O Balanced Scorecard permite tornar os objetivos financeiros explícitos, e ajustados às unidades de negócio nas diferentes fases do seu crescimento e ciclo de vida. Alguns exemplos de estratégias que direcionam os objetivos financeiros do 
BSC nesta perspectiva podem ser citados:

Para empresas em crescimento, o aumento das vendas em novos mercados e para novos clientes gerando novos produtos e serviços;

Para empresas em sustentação, o retorno sobre o capital empregado, a receita operacional e a margem bruta. Projetos de investimento serão analisados por métodos tradicionais de fluxo de caixa descontado e orçamento de capital. Objetivando o melhor retorno sobre o capital investido na empresa;

Para empresas em colheita, o fluxo de caixa. Qualquer investimento deve ter retorno certo e imediato. A meta é maximizar a geração de caixa como conseqüência de todos os investimentos feitos no passado. Neste tipo de empresa não há despesas com Pesquisa e Desenvolvimento ou com ampliação da capacidade.

Existem três temas financeiros que norteiam a estratégia empresarial, o mix de receita, redução de custos / melhoria da produtividade e a utilização dos ativos I estratégia de investimentos. Esta perspectiva do BSC preocupa-se em retratar as estratégias da empresa nestes três temas.

Perspectiva dos Clientes: A perspectiva dos clientes permite o alinhamento das empresas com segmentos específicos de clientes e mercados, utilizando as seguintes medidas de resultado relacionadas aos clientes:

Medidas essenciais dos clientes: Participação de mercado, captação de clientes, retenção de clientes, satisfação dos clientes e lucratividade com os clientes;

Medidas de proposta de valor: Atributos dos produtos / serviços, relacionamento com os clientes, imagem e reputação.

Dentro desta perspectiva é de fundamental importância o entendimento do conceito de proposição de valor. Para a Symnetics Business Transformation (2004), proposição de valor é o conjunto de atributos requeridos pelos clientes que integram um determinado segmento de mercado. Identificar a proposição de valor viabiliza o entendimento de quais são os segmentos de mercado onde a empresa atua e quais poderiam ser os grandes planos de ação para se atingir os requerimentos destes clientes. Ela também viabiliza a eventual identificação de novos segmentos de atuação ou novos critérios para se segmentar os atuais clientes; e a definição de estratégias ou planos de ação comuns para segmentos ou grupos de clientes que apresentem os mesmos requerimentos.

Perspectiva dos Processos Internos da Empresa: Os objetivos e medidas para a perspectiva dos processos internos derivam de estratégias explícitas voltadas para o atendimento às expectativas dos acionistas e clientes alvo. A análise seqüencial, de cima para baixo, costuma revelar processos de negócios inteiramente novos nos quais a empresa deverá buscar a excelência. Uma cadeia de valor completa dos processos internos deve ser definida para que os objetivos estratégicos possam ser avaliados e associados a cada elo da cadeia de valor.

Perspectiva do Aprendizado e Crescimento: Os objetivos desta perspectiva oferecem a infra-estrutura necessária para a realização dos objetivos das outras três perspectivas, além de serem os vetores de resultados das três outras. Estes vetores podem ser classificados da seguinte forma:

Capacidade dos funcionários: As idéias que permitem melhorar os processos e o desempenho para da empresa cada vez mais emanam dos funcionários da linha de frente, que se encontram mais próximos dos processos internos e dos clientes;

Capacidade dos sistemas de informação: 
Para que as pessoas tenham boa performance no ambiente competitivo de hoje, precisam de informações precisas e atualizadas sobre os clientes, os processos internos e as conseqüências financeiras de suas ações;

Motivação, delegação e alinhamento: $\mathrm{O}$ terceiro vetor dos objetivos de aprendizado e crescimento focaliza o clima organizacional para motivação e a iniciativa dos funcionários. Mesmo funcionários habilitados, que disponham de excelente acesso às informações, não contribuirão para o sucesso organizacional se não forem motivados a agir no melhor interesse da empresa, ou se não tiverem liberdade para decidir ou agir.

Depois de definidas as quatro perspectivas do Balanced Scorecard, um segundo conceito de grande importância nesta ferramenta é o que aponta para a tradução da estratégia em termos operacionais. Conforme pode ser visto na figura 3.

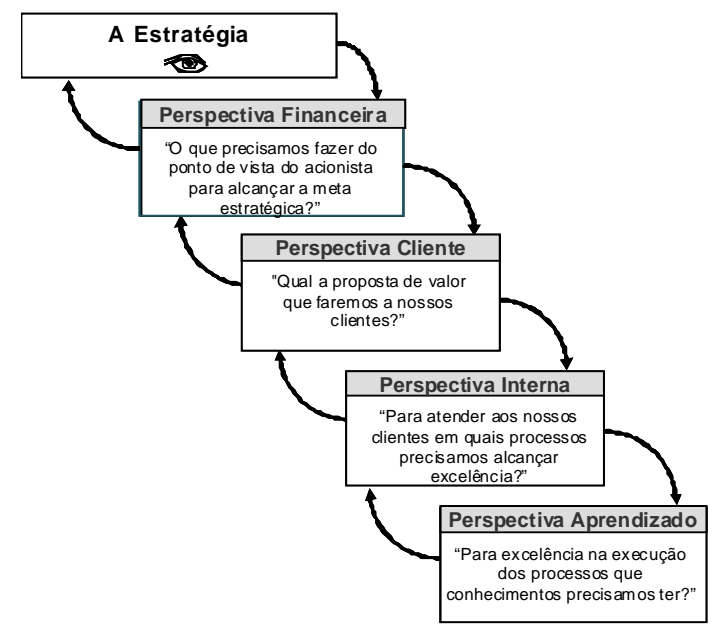

Fonte: Adaptado de Kaplan e Norton (2004), p. 8

Figura 3: Relação de causa e efeito entre as perspectivas do Balanced Scorecard

A estratégia deve comunicar as séries de relações de causa e efeito existentes entre as perspectivas do BSC. Rampersad (2004) afirma que todos os objetivos estratégicos devem ser integrados e afetar uns aos outros. Utilizam-se os objetivos para atingir outros objetivos, que por sua vez levarão ao objetivo final da organização. Os elos entre os diferentes objetivos tornam-se claros por meio da cadeia de causa e efeito, que é uma ferramenta útil no desdobramento do BSC para os níveis mais baixos da organização.

A mensuração, os indicadores, bem como as metas envolvidas em cada uma destas perspectivas, são usados para comunicar à organização aonde se deseja chegar, bem como onde se está ao longo de um período. Esta mensuração traz clareza às concepções e cria a sinergia necessária ao alinhamento de toda a organização em direção à estratégia definida e planejada (KAPLAN e NORTON, 2004).

\section{COMPARANDO A ABRANGÊNCIA DE CADA UM DOS TRÊS MODELOS}

A FDC procurou avaliar as respostas relativas a quinze quesitos, na amostra utilizada, reproduzidos a seguir, comparando três modelos abrangentes e mais utilizados pelas grandes empresas de avaliação de performance: O BSC, o TQC e o PNQ. Este estudo complementou esta comparação, agrupando os resultados obtidos na pesquisa, por outras ferramentas, classificando-as num quarto item: OUT, que contempla o conjunto de indicadores clássicos utilizados de forma mais tradicional pelas empresas.

QUESITO 1 - Facilita a tradução da visão; QUESITO 2 - Orienta o processo de formulação da estratégia; QUESITO 3 - Promove o alinhamento do corpo executivo em relação à estratégia; QUESITO 4 - Facilita o processo de comunicação em todos os níveis da empresa; QUESITO 5 - Tem instrumentos adequados ao desdobramento da Estratégia; QUESITO 6 - Estimula a criatividade em todos os níveis da Organização; QUESITO 7 Facilita a elaboração e a implementação de Planos de Ação; QUESITO 8 Favorece a escolha de indicadores compatíveis com a estratégia; QUESITO 9 - Induz uma sistemática de 
acompanhamento e ações corretivas; QUESITO 10 - Favorece a aprendizagem do processo de formulação, implementação e avaliação da estratégia; QUESITO 11 - Permite a vinculação a modelos de remuneração variável ou formas de reconhecimento; QUESITO 12 - Promove a compatibilização dos planejamentos e controles de curto e longo prazo; QUESITO 13 - Fornece uma leitura adequada aos acionistas; QUESITO 14 - Contempla todos os "stakeholders"; QUESITO 15 Possibilita simulação de opções estratégicas.

Tanto as empresas que utilizam indicadores financeiros clássicos, como aquelas que utilizam indicadores operacionais como o principal instrumento de avaliação de desempenho, indicaram que os quesitos menos atendidos são:

- Quesito 6: Estimula a criatividade em todos os níveis da organização,

- Quesito 14: Contempla todos os stakeholders e

- Quesito 15: Possibilita simulação de opções estratégicas.

Já os quesitos mais bem atendidos são:

- Quesito 7: Facilita a elaboração e implementação de planos de ação e

- Quesito 13: Fornece uma leitura adequada aos acionistas.

A seguir, são apresentados na figura 4, sob a forma de diagramas tipo radar, com escala de 6 a 10, estes 5 quesitos (3 menos e 2 mais bem atendidos), com as melhores médias de avaliação, apresentadas pelas empresas que utilizam cada um dos modelos pesquisados.
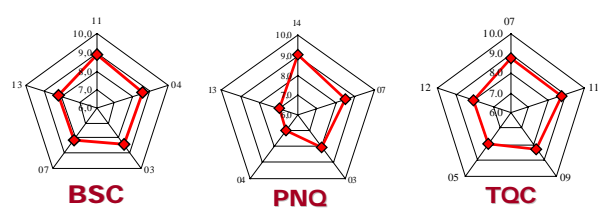

Fonte: FDC - Pesquisa Modelos de Avaliação de Desempenho Empresarial Figura 4: Quesitos Menos e Mais Atendidos, Segundo as Empresas Entrevistadas
Com base nas avaliações das empresas que responderam à pesquisa, pode-se compor uma matriz comparativa das ferramentas avaliadas, conforme pode ser visto na tabela 1 deste estudo.

Tabela 1: Matriz Comparativa das Ferramentas Avaliadas

\begin{tabular}{|c|c|c|c|c|c|}
\hline $\mathrm{N}^{\mathrm{O}}$ & Quesitos & BSC & PNQ & TQC & Outros \\
\hline 1 & Facilita a Tradução da Visão & 8,5 & 5,0 & 5,0 & 4,0 \\
\hline 2 & $\begin{array}{l}\text { Orienta o Processo de Formulação } \\
\text { da Estratégia }\end{array}$ & 7,5 & 5,0 & 4,5 & 6,0 \\
\hline 3 & $\begin{array}{l}\text { Promove o Alinhamento do Corpo } \\
\text { Executivo em relação à Estratégia }\end{array}$ & 9,0 & 7,0 & 6,0 & 8,0 \\
\hline 4 & $\begin{array}{l}\text { Facilita o Processo de } \\
\text { Comunicação em Todos os Níves } \\
\text { da Empresa }\end{array}$ & 8,5 & 8,0 & 8,0 & 5,0 \\
\hline 5 & $\begin{array}{l}\text { Tem Instrumentos Adequados ao } \\
\text { Desdobramento da Estratégia }\end{array}$ & 8,5 & 3,0 & 7,5 & 4,0 \\
\hline 6 & $\begin{array}{l}\text { Estimula a Criatividade em Todos } \\
\text { os Níveis da Organização }\end{array}$ & 8,0 & 6,0 & 9,0 & 6,0 \\
\hline 7 & $\begin{array}{l}\text { Facilita a Elaboração e a } \\
\text { Implementação dos Planos de } \\
\text { Ação }\end{array}$ & 9,0 & 8,0 & 8,5 & 4,0 \\
\hline 8 & $\begin{array}{l}\text { Favorece a Escolha de Indicadores } \\
\text { Compatíveis com a Estratégia }\end{array}$ & 9,0 & 6,5 & 6,0 & 5,0 \\
\hline 9 & $\begin{array}{l}\text { Induz uma Sistemática de } \\
\text { Acompanhamento e Ações } \\
\text { Corretivas }\end{array}$ & 8,5 & 7,5 & 9,0 & 3,5 \\
\hline 10 & $\begin{array}{l}\text { Favorece a Aprendizage do } \\
\text { Processo de Formulação, } \\
\text { Implementação e Avaliação da } \\
\text { Estratégia }\end{array}$ & 8,0 & 7,5 & 4,5 & 5,5 \\
\hline 11 & $\begin{array}{l}\text { Permite a Vinculação a Modelos de } \\
\text { Remuneração Variável ou Formas } \\
\text { de Reconhecimento }\end{array}$ & 9,5 & 6,5 & 9,0 & 9,0 \\
\hline 12 & $\begin{array}{l}\text { Promove a Compatibilização dos } \\
\text { Planejamentos e CobControles de } \\
\text { Curto e Longo Prazos }\end{array}$ & 8,0 & 5,5 & 7,5 & 8,0 \\
\hline 13 & $\begin{array}{l}\text { Fornece uma Leitura Adequada } \\
\text { aos Acionistas }\end{array}$ & 9,0 & 7,0 & 5,0 & 9,5 \\
\hline 14 & Contempla todos os "Stakeholders" & 8,5 & 8,5 & 7,0 & 4,0 \\
\hline 15 & $\begin{array}{l}\text { Possibilita Simulação de Opções } \\
\text { Estratégicas }\end{array}$ & 8,0 & 2,0 & 4,0 & 9,0 \\
\hline & Média dos Quesitos Selecionados & 8,80 & 6,60 & 7,30 & 7,00 \\
\hline
\end{tabular}

Fonte: FDC - Adaptado da Pesquisa Modelos de Avaliação de Desempenho

Aqui faz-se necessário um recorte dos dados levantados na pesquisa da FDC visando $\mathrm{o}$ atendimento dos interesses deste estudo. Considerando-se apenas os quesitos relevantes ao controle de 
desempenho, esquecendo-se do desenvolvimento e acompanhamento da estratégia, pode-se selecionar alguns itens da tabela 1, obtendo-se uma comparação das ferramentas apenas à luz de sua função de controle de desempenho, aproveitando os quesitos 8, 9, 11, 12 e 13 e ignorando-se os demais.

Observa-se que as médias de todas as ferramentas melhoram quando se concentra a avaliação na área de controle de desempenho, o que faz sentido, à medida que a experiência das grandes empresas com formas de controle precede sua experiência com planejamento estratégico. Outro fato bastante significativo é que o Balanced Scorecard, comumente vendido como uma ferramenta de acompanhamento da estratégia, tem sua pontuação majorada em mais de $10 \%$ em média, quando avaliadas apenas as respostas dos quesitos relacionados ao controle de desempenho.

Também é interessante observar que apesar do PNQ ter incorporado nos últimos anos, muitas das inovações trazidas pelo "Balanced Scorecard" em termos de avaliação do desempenho e de indução de melhorias no desempenho empresarial, sua pontuação é inferior não só ao seu modelo inspirador, o TQC, como também à média das ferramentas mais tradicionais que combinam indicadores financeiros, de produção e de mercado.

Como visto na tabela 1 , o BSC não só tem maior pontuação que as outras ferramentas, dada pelas 98 empresas que responderam ao questionário com respostas válidas, como também as tem no subconjunto de respostas associadas ao controle de desempenho de suas organizações. Entretanto, para que esta maior abrangência apontada em favor do BSC seja completamente validada, o estudo requer uma análise simultânea das variáveis escolhidas para representar a grandeza controle de desempenho das organizações, buscando entender a influência de umas sobre as outras. Esse fato levou o pesquisador a recorrer a uma análise que cruza todas as respostas das 98 empresas nos quesitos $8,9,11,12,13$, para que se tenha uma dimensão explicativa adicional. Assim sendo, o conceito de correlação precisa ser entendido e exercitado através da Correlação de Pearson.

A análise de correlação visa determinar a força de relacionamento entre duas variáveis quantitativas. $\mathrm{O}$ termo correlação significa, literalmente, "corelacionamento", ou seja, uma "relação conjunta", indicando até que ponto os valores de uma variável (X) estão relacionados com os de outra (Y). A interpretação desse relacionamento deve ser feita com cautela, posto que pode não existir uma relação causal entre as variáveis de interesse. O relacionamento matemático permite predizer valores de uma delas com base no conhecimento da outra, mas nada informa quanto à causa e efeito. Praticamente, o Coeficiente de Correlação determina o grau de dispersão dos valores em torno da reta, permitindo interpretar a probabilidade desta ser fiel à relação em estudo. Quanto mais próximo este coeficiente estiver da unidade (positivo ou negativo), mais perfeita será a correlação entre as variáveis. Um coeficiente de correlação nulo sugere existência de dissociação, não havendo nenhuma correlação linear. A correlação positiva sugere que um aumento em $X$ proporciona também crescimento em $\mathrm{Y}$.

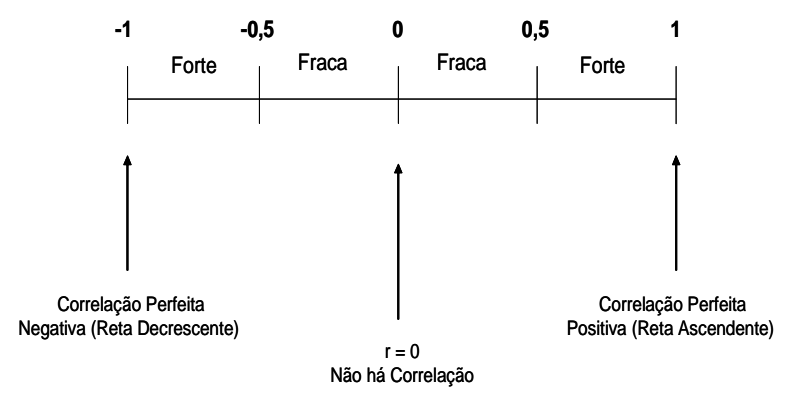

Fonte: Gassenferth (2005, p.103)

Figura 5: Escala de Variação do Coeficiente de Pearson

Duas variáveis estão correlacionadas negativamente, caso ocorra uma relação inversa entre as variáveis. A forma mais 
comum de análise de correlação envolve duas variáveis quantitativas contínuas. $\mathrm{O}$ grau de correlação neste caso é sintetizado pelo Coeficiente de Correlação de Pearson (r). A figura 5 mostra quando uma correlação entre duas variáveis é forte e quando é fraca.

Utilizando-se o software Unistat 5.5, similar ao SPSS, para fazer as correlações das variáveis duas a duas, encontraram-se os seguintes resultados para um intervalo de confiança de $95 \%$ :

$$
\begin{aligned}
& \text { Quesito } 8 \text { e Quesito } 9 \rightarrow r=0,7221 \\
& \text { Quesito } 9 \text { e Quesito } 12 \rightarrow r=0,8021 \\
& \text { Quesito } 8 \text { e Quesito } 11 \rightarrow r=0,7199 \\
& \text { Quesito } 9 \text { e Quesito } 13 \rightarrow r=0,6341 \\
& \text { Quesito } 8 \text { e Quesito } 12 \rightarrow r=0,7669 \\
& \text { Quesito } 11 \text { e Quesito } 12 \rightarrow r=0,5882 \\
& \text { Quesito } 8 \text { e Quesito } 13 \rightarrow r=0,8606 \\
& \text { Quesito } 11 \text { e Quesito } 13 \rightarrow r=0,7524 \\
& \text { Quesito } 9 \text { e Quesito } 11 \rightarrow r=0,5024 \\
& \text { Quesito } 12 \text { e Quesito } 13 \rightarrow r=0,7455
\end{aligned}
$$

Todos os resultados estão acima de $+0,5$, ou seja, mostram uma correlação positiva entre as variáveis utilizadas para demonstrar a abrangência do BSC para controle de desempenho, na opinião das 98 empresas entrevistadas que tiveram suas respostas validadas pela pesquisa.

\section{CONCLUSÕES E RECOMENDAÇÕES}

Um estudo descritivo, em essência, visa observar, registrar, analisar e correlacionar fatos ou fenômenos (variáveis) sem manipulá-los. $\mathrm{Na}$ tentativa de atender ao objetivo proposto, este estudo procurou mostrar a utilização dada ao Balanced Scorecard como ferramenta de controle de desempenho, pelas grandes empresas que operam no mercado brasileiro. Neste caminho, verificou-se que o BSC é a ferramenta que possui as características mais abrangentes às necessidades de controle de desempenho de uma organização, na opinião da maior parte das 500 maiores empresas do mercado brasileiro, estatisticamente falando. Percebe-se, a partir dos dados levantados no trabalho, a versatilidade do BSC. As empresas entrevistadas deram ampla vantagem ao Balanced Scorecard em suas respostas, caracterizando a estrutura mais abrangente desta ferramenta.

Pode-se também observar no desenvolvimento do trabalho, que o BSC, apesar de ser comercializado hoje como uma ferramenta que serve diretamente à estratégia, apresenta uma vocação de berço para o controle e avaliação de desempenho, trazendo consigo uma vantagem nesta aplicação: Sendo utilizado com esta finalidade, não necessita ser implantado em toda a empresa, servindo aos interesses imediatos de controle e reorganização de uma unidade de negócios, mas ao mesmo tempo, criando uma cultura, onde a utilização dos Scorecards servirá de preparação para um uso mais ostensivo, voltado aos interesses estratégicos da empresa, mais tarde. Esta variante no uso da ferramenta, aponta para a recomendação do uso do BSC como ferramenta de controle de desempenho em empresas que possuam unidades que necessitem de uma maior visibilidade de seu processo produtivo ou uma melhor forma de controle, preparando-as para um futuro planejamento integrado de toda a empresa.

Como limitação deste estudo, pode-se afirmar que o mesmo não pode ser utilizado para concluir ou propor recomendações às organizações que não sejam àquelas de grande porte em nosso país, conforme a intenção original do pesquisador.

\section{BIBLIOGRAFIA}

BANKER, T, R. D.; POTTER, G.; SRINIVASAN, D. "An investigation of an incentive plan that includes nonfinancial performance measures”. In: The 
Accounting Review, V.75, $\mathrm{n}^{0} .1$, p.65-92, 2000.

CAMPOS, Vicente Falconi .Gerenciamento pelas Diretrizes. Belo Horizonte: Fundação Christiano Ottoni Escola de Engenharia da UFMG, 1996.

CERTO, S. C. e PETER, J. P. Administração Estratégica Planejamento e Implantação da Estratégia. Trad. Flávio Denin Steffen. São Paulo: Makron Books, 1993.

FPNQ, Fundação Para o Prêmio Nacional da Qualidade. Critérios de Excelência O Estado da arte da Gestão para a Excelência do Desempenho. São Paulo: FPNQ, 2004.

FPNQ, Fundação Para o Prêmio Nacional da Qualidade. Planejamento do Sistema de Medição do Desempenho. $2^{\mathrm{a}}$ ed. São Paulo: FPNQ, 2003.

GASSENFERTH, Walter. O Uso do Balanced Scorecard como Ferramenta de Controle de Desempenho pelas Controladorias de Grandes Organizações do Mercado Brasileiro. Rio de Janeiro: IBMEC-RJ. Dissertação de Mestrado em Administração, Defendida e Aprovada no Programa de Pós Graduação e Pesquisa em Administração e Economia das Faculdades IBMEC, 2005.

HRONEC, S. M. Sinais Vitais: Usando Medidas do Desempenho da Qualidade, Tempo e Custo para Traçar a Rota para o Futuro de sua Empresa. São Paulo: Makron Books, 1994.

ITTNER, C. D. e LARCKER, D. F. “Are non-financial measures leading indicators of financial performance: an analysis of customer satisfaction". In: Journal of
Accounting Research, V.36, p.1-35, 1998.

KAPLAN, Robert S. e NORTON, David P. "Using the Balanced Scorecard as a Strategic Management System”. In: Harvard Business Review. Boston: V. Jan/Fev, p75-86, 1996.

KAPLAN, Robert S. e NORTON, David P. A Estratégia em Ação. Trad. Luiz Euclydes Trindade Frazão Filho. Rio de Janeiro: Editora Campus, 1997.

KAPLAN, Robert S. e NORTON, David P. Mapas Estratégicos Convertendo Ativos Intangíveis em Resultados Tangíveis. Trad. Afonso Celso da Cunha Serra. Rio de Janeiro: Editora Campus, 2004.

MERCHANT, Kenneth A. "The Control Function of Management”. In: Sloan Management Review. Boston: V.23, n.4, p.43-55, 1982.

RAMPERSAD, Hubert K. Scorecard para Performance Total. Trad. Afonso Celso da Cunha Serra. Rio de Janeiro: Editora Campus, 2004.

SHARMAN, Paul. "How to Implement Performance Measurement in Your Organization”. In: Certified Managements Accountants Magazine. Ontario, Canadá, V.39, p.33-37. Maio de 1995.

SINK, Scott e TUTTLE, Thomas C. Planning and Measurement in Your Organization of the Future. Norcross, Georgia: Industrial Engineering and Management Press, 1989.

Symnetics Business Transformation [Home]. Disponível: http://www.symnetics.com.br, Consulta: 08 de Maio de 2004. 